\title{
Experimental study of the behaviour of cement pastes in the presence of carbon nanotubes
}

\author{
Ritoltas Šukys ${ }^{1}$, Jolanta Pranckevičiené2 ${ }^{2}$, Giedrius Girskas ${ }^{3}$, Ina Pundiené ${ }^{4}$, \\ Dainius Leonavičius ${ }^{5}$, Modestas Kligys ${ }^{6}$ \\ ${ }^{I}$ Department of Building Materials and Fire, Faculty of Civil Engineering, \\ Vilnius Gediminas Technical University, Vilnius, Lithuania

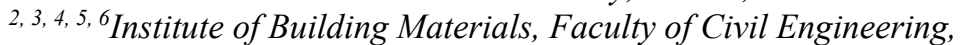 \\ Vilnius Gediminas Technical University, Vilnius, Lithuania \\ E-mail: ${ }^{5}$ dainius.leonavicius@vgtu.lt (corresponding author)
}

\begin{abstract}
One of the methods recently applied for the noticeably improvement of properties of cementitious materials is the use of the single or multi-walled carbon nanotubes (CNTs) as nano-reinforcements in cementitious materials. The positive action of CNTs highly depends not only on its nature, length and amount, but also on previous treatment of CNTs and quality of CNTs dispersion. It is important to obtain the effects of multi-walled CNTs, dispersed only in carboxyl-methyl cellulose - commercially available pellets without the use of any commercially available surfactants or plasticizers. The influence of dispersed CNTs on the rheological properties of fresh cement pastes and physical and mechanical properties of hardened specimens was analyzed in this work. Compared to the dynamic viscosity of pure distilled water smaller amounts of CNTs $(0.00005-0.005 \%)$ reduce the dynamic viscosity down to the $15 \%$ whereas higher amounts of CNTs $(0.05-0.5 \%)$ increase the dynamic viscosity from 1.3 to 4.7 times. Mechanical tests of hardened for 28 days cement paste specimens showed that smaller amounts of CNTs $(0.00005-0.005 \%)$ increase the compressive and flexural strengths by $38.07-42.3 \%$ and $40.1-44.6 \%$, whereas higher amounts of CNTs $(0.05-0.5 \%)$ increase these strengths just by $21.11-18.82 \%$ and $18.33-6.6 \%$ respectively.
\end{abstract}

Keywords: multi-walled carbon nanotubes, fresh cement paste, dynamic viscosity, hardened cement paste, mechanical strength.

\section{Introduction}

Carbon nanotubes are a form of carbon which was first discovered in 1952 in Russia, but mostly ignored, then rediscovered in the 1991 at NEC's Fundamental Research Lab in Japan as a minor by-product of fullerene synthesis (Sumio, 1991). The structure of CNTs consists of nano-dimensions made up of rolled sheets of graphite. There are many ways of which a sheet of graphite is rolled up to form a tube such as zigzag, chiral and armchair are the names given to different types (Esawi \& Farag, 2007). Verities of CNTs include single-walled nanotubes and multi-walled nanotubes. Single-walled nanotubes were discovered in 1993, they have only one wall which constitutes a tube, whilst multi-walled nanotubes have multi walls which can slide against other. The diameter of CNTs are on the scale of 1$100 \mathrm{~nm}$, which are small that 50000 of them could reach the diameter of one human hair. The surface area typically is in the range of $\sim 100000-700000 \mathrm{~m}^{2} / \mathrm{kg}$ (Peigney, Laurent, Flahaut, Bacsa, \& Rousset, 2001). For single-walled nanotubes, the diameters of tubes in the range of few nanometers $(1-10 \mathrm{~nm})$, whilst they reached several tens of nanometers $(5-100 \mathrm{~nm})$ in the case of multi-walled nanotubes because their structure consists of many concentric cylinders held together by van der Waals forces (He, Kitipomchai, \& Leiw, 2005), but they are less effective than those of singlewalled nanotubes. The multi shell structure of multi-walled nanotubes is stiffer than the single-wall ones, especially in compression. Multi-walled nanotubes usually maintain the inter shell spacing close to that of the graphite inter-layer spacing of $0.335 \mathrm{~nm}$ (Lavin, Subramoney, Ruoff, Berber, \& Tománek, 2002). Another advantage of multi-walled nanotubes over those of single-walled nanotubes is that large-scale synthesis can be easily achieved by performing several enhanced chemical vapor deposition method (Bandow et al., 2002). It is worth mentioning that multi-walled nanotubes are less expensive and more readily available than those of single-walled nanotubes. CNTs are widely considered to be the one of the prospective materials of the 21st century and bring new patterns to structural integrity (Liu, Zheng, Wang, \& Jiang, 2005), cement-based materials (Sobolev \& Shah, 2015) and other fields (Bandaru, 2007; Malarkey \& Parpura, 2007; Harrison \& Atala, 2007).

(C) 2019 Authors. Published by VGTU Press. This is an open-access article distributed under the terms of the Creative Commons Attribution (http://creativecommons.org/licenses/by/4.0/) License, which permits unrestricted use, distribution, and reproduction in any medium, provided the original author and source are credited. 
The use of nanotechnologies to improve the properties of cementitious systems is a rapidly developing area. Reinforcement of cementitious materials with different kind of fibers (such as polypropylene and nylon), natural cellulose (such as hardwood and softwood pulps), and inorganic fibers (such as steel, glass and carbon) is a common method to control the cracking processes (Musso, Tulliani, Ferro, \& Tagliaferro, 2009). That is why CNTs are potential candidates for use as resistance to crack propagation additive (Makar, Margeson, \& Luh, 2005; Li, Wang, \& Zhao, 2007). CNTs have gained the interest of researchers for their noticeable high mechanical and tensile strength, thermal and unique electrical and chemical properties (Ajayan, 1999; Salvetat et al., 1999; Srivastava, Wei, \& Cho, 2003; Makar \& Beaudoin, 2003; Campillo, Dolado, \& Porro, 2003; Li, Wang, \& Zhao, 2005; Cwirzen et al., 2009; Cwirzen, Habermehl-Cwirzen, \& Penttala, 2008; Yakovlev, Keriene, Gailius, \& Girniene, 2006). Researchers (Cwirzen et al., 2009,2008 ) have reported the increase (approx. 50\%) in compressive strength of cement paste specimens when $0.045-$ $0.15 \%$ of CNTs (by weight of cement) was added to the forming mixture. Approximately $70 \%$ (from 0.18 to $0.306 \mathrm{MPa}$ ) increase in compressive strength of cementitious foamed concrete specimens was obtained when $0.05 \%$ of CNTs (by weight of cement) was used in the forming mixture (Yakovlev et al., 2006). A significant reduction of the average pore diameter was observed in the specimens. A study (Laukaitis, Keriene, Kligys, Mikulskis, \& Lekunaite, 2012) reports a considerable increase of crystallinity and compressive strength as well as decrease of thermal deformation in autoclaved aerated concrete specimens upon the addition of $0.1 \%$ (by weight of binder) of crushed carbon fibers.

CNTs production methods and forms (pellets, solutions or powders) can definitely affect the rheological properties of cementitious materials. In general, plasticizers in cementitious materials with CNTs additive are used. The aim of this paper was to estimate the influence of CNTs, used in different amounts ( $0 \%$ to $0.5 \%$ by weight of cement) on rheological properties of the fresh cement paste and physical or mechanical properties of the hardened cement paste specimens. It is important to determine the optimal amount of CNTs to be added to fresh cement pastes in order to improve the properties listed above.

\section{Materials and methods of testing}

GRAPHISTRENGTH CW2-45 pellets containing multi-walled CNTs of about $90 \%$ purity at $45 \%$ concentration (by weight), dispersed in carboxyl-methyl cellulose at 55\% content (by weight) provided by ARKEMA company were immersed in $100 \mathrm{ml}$ of hot $\left(95-100^{\circ} \mathrm{C}\right.$ ) distilled water for $10 \mathrm{~min}$ (without mixing) and subjected to ultrasonic treatment for 5 min (disperser UZDN-2T). Prepared CNTs water solutions were diluted (according to the fresh cement paste composition) and measured. The same CNTs water solutions were used for preparation of fresh cement pastes. Ordinary Portland cement (OPC) CEM I $42.5 \mathrm{R}$, specific surface of $3190 \mathrm{~cm}^{2} / \mathrm{g}$ was used. Mineral composition of clinker (in.): $\mathrm{C} 3 \mathrm{~S}-63.98 ; \mathrm{C} 2 \mathrm{~S}-7.74$; $\mathrm{C} 3 \mathrm{~A}-6.38 ; \mathrm{C} 4 \mathrm{AF}-12.68$. Water to cement ratio in all specimens was the same (0.3). The amount of CNTs in the forming mixture varied from 0.00005 to $0.50000 \%$ (by weight of OPC) (see Table 1). The specimens were made and cured in compliance with EN 12390-2:2009. The specimens of $40 \times 40 \times 160 \mathrm{~mm}$ dimensions were kept in molds for 1 day in normal conditions and then hardened in water at $20^{\circ} \mathrm{C}$ temperature for 27 days.

Table 1. The amount of CNTs in the water solutions (a) and fresh cement pastes with constant water to cement ratio (b)

\begin{tabular}{|c|c|c|c|}
\hline Specimen series & OPC, $\%$ & (a) CNTs, $\%$ & (b) CNTs, $\%$ \\
\hline CNTs-0 & 100 & 0.00000 & 0.00000 \\
\hline CNTs-1 & 100 & 0.00017 & 0.00005 \\
\hline CNTs-2 & 100 & 0.00170 & 0.00050 \\
\hline CNTs-3 & 100 & 0.01700 & 0.00500 \\
\hline CNTs-4 & 100 & 0.1700 & 0.05000 \\
\hline CNTs-4 & 100 & 1.7000 & 0.50000 \\
\hline
\end{tabular}

The effect of different amounts of CNTs on the dynamic viscosity of water solutions and fresh cement pastes was tested using the vibro-viscometer SV-10 (capacity - up to $12.000 \mathrm{mPa} \cdot \mathrm{s}$, accuracy $-0.01 \mathrm{mPa} \cdot \mathrm{s}$ ). The dynamic viscosity of water solutions and fresh cement pastes was measured immediately after the preparation and during 30 minutes.

Strength tests were performed with ALPHA 3-3000 S testing machine. Arithmetic averages of each 5 successful measurements are presented in the paper. The conventional tests were done in compliance with the following standards: EN 12390-3:2009, EN 12390-7:2009, EN 196-6:2010, EN ISO 1927-1:2012, EN 1402-6. 


\section{Research results and discussion}

The studies of dynamic viscosity of water solutions have been carried out. The measurements of water solutions (Figure 1a) showed that smaller amounts (0.00017-0.017\%) of CNTs decrease the dynamic viscosity down to the $15 \%$ compared to the viscosity of pure distilled water. In case when higher $(0.17 \%)$ and the highest $(1.7 \%)$ amounts of CNTs were used increased the dynamic viscosity of water solutions up to $30 \%$ and by 4.7 times compared to the dynamic viscosity of pure distilled water were observed. This increase may have been influenced by carboxyl-methyl cellulose, used in the production of the pellets containing CNTs. It is known that carboxyl-methyl cellulose acts as a thickener in water solutions. However, in water solutions with small $(0.00017-0.017 \%)$ amounts of CNTs opposite processes occur and dynamic viscosity of the solutions decreases.

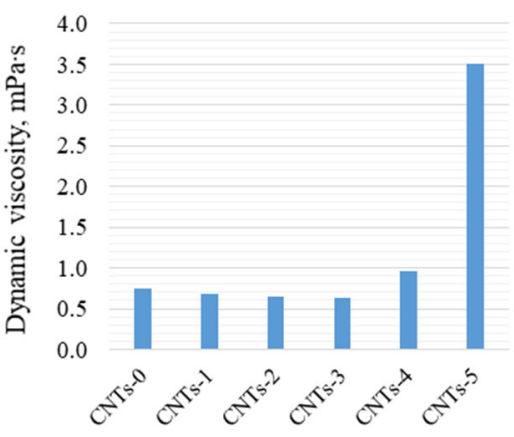

a)

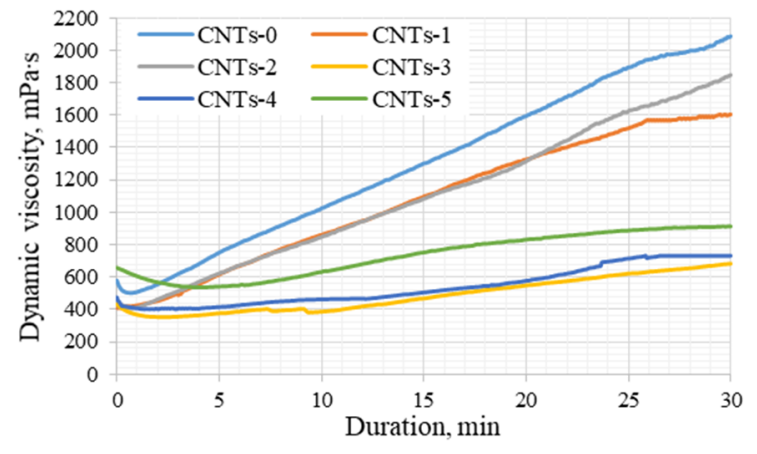

b)

Figure 1. Dynamic viscosity: (a) water solutions; (b) fresh cement pastes

It was determined that the initial dynamic viscosity in control paste (CNTs-0) rose to $610 \mathrm{mPa} \cdot \mathrm{s}$ after mixing, and within 30 minutes, it increased until the highest value $-2100 \mathrm{mPa} \cdot \mathrm{s}$. When smaller amounts of CNTs $(0.00005$ and $0.00050 \%)$ were used in fresh cement pastes, the initial dynamic viscosity decreased to $400 \mathrm{mPa} \cdot \mathrm{s}$ (approximately 20\%). Practically, there was no difference in the dynamic viscosity between both fresh cement pastes within 20 minutes. During the last 10 minutes of the experiment, the dynamic viscosity in pastes CNTs-1 and CNTs-2 reached $1.610 \mathrm{mPa} \cdot \mathrm{s}$, and $1.870 \mathrm{mPa} \cdot \mathrm{s}$ respectively. The lowest dynamic viscosity was observed in paste CNTs-3, where the change in dynamic viscosity during 30 minutes was from 390 to $570 \mathrm{mPa} \cdot \mathrm{s}$ (Figure $1 \mathrm{~b}$ ).

Tests after two days of curing (see Figure $2 \mathrm{a}$ ) showed that the compressive strength of specimen CNTs-0 reached $61 \mathrm{MPa}(0 \%) .7 .2 \%$ growth in compressive strength was observed in specimens, where CNTs amount in the mix was increased up to $0.005 \%$. When CNTs amount in the mix reaches $0.05000 \%$ and $0.50000 \%$, the compressive strength of the specimens drops accordingly by $5 \%$ and $10 \%$ compared to the strength of specimen CNTs-0. The same tendencies were observed after 7 days of curing. The increase in CNTs amount within range $0.00005-0.00500 \%$ increases the compressive strength up to 27.66 to $32.57 \%$, compared to the strength of the control specimen $(22.7 \%)$. Higher amounts of CNTs $(0.05000 \%$ and $0.50000 \%)$ increase the compressive strength just by $17.84 \%$ and $15.6 \%$ respectively.

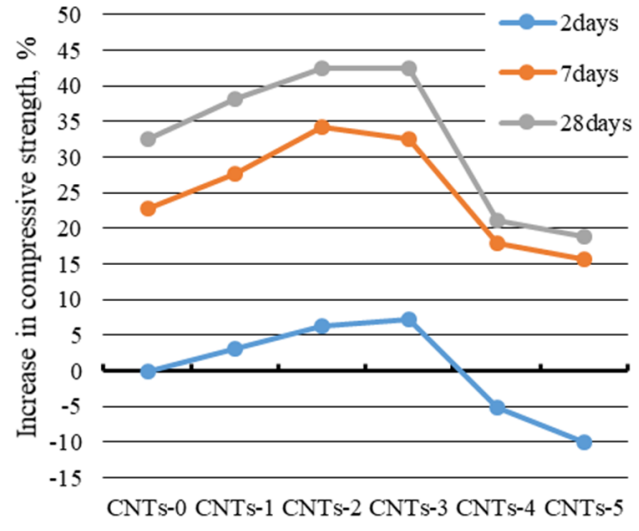

a)

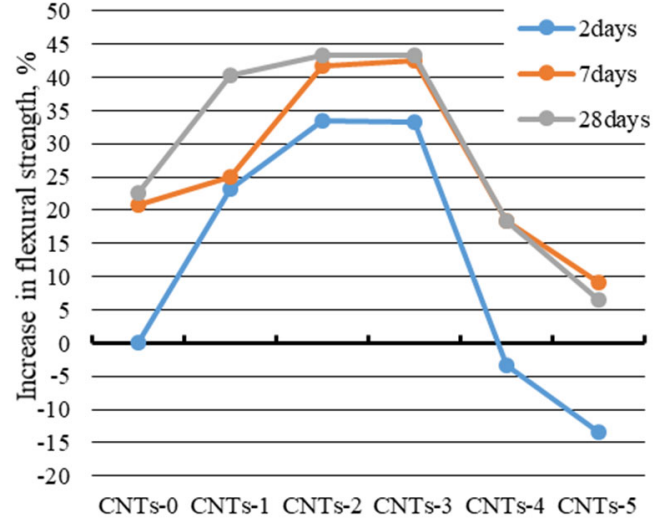

b)

Figure 2. Increase in strength: (a) compressive; (b) flexural 
After 28 days of curing the compressive strength of specimens containing $0.00005-0.0005 \%$ of CNTs increases by $38.07 \%$ and $42.39 \%$ compared to the control specimen, whereas higher amounts of CNTs $(0.05000 \%$ and $0.50000 \%$ ) increase the compressive strength just by $22 \%$. These results indicate that during the hardening period of 2-28 days, smaller amounts of CNTs (up to $0.00500 \%$ ) significantly increase the compressive strength whereas higher amounts of CNTs does not have a significant impact on the compressive strength. The same tendency for smaller amounts of CNTs $(0.025 \%, 0.05 \%$ and $0.1 \%)$ was observed in other research (Xu, Liu, \& Li, 2015). The aforementioned results and references lead to the conclusion that if the amount of the CNTs in composition of the mix exceeds $0.00500 \%$, a reduction in compressive strength can be predicted.

The same tendencies were observed in testing results of flexural strength (see Figure $2 \mathrm{~b}$ ). After two days of curing the flexural strength in specimens containing smaller amounts of CNTs increased up to $33.3 \%$, whereas in specimens with higher amounts of CNTs, the strength decreased by $3.4 \%$ and $13.3 \%$ compared to the control specimen. After seven days of curing the difference in flexural strength between the control specimen (20\%) and specimens containing smaller amounts of CNTs sometimes reached $42.5 \%$, while the flexural strength of specimens containing higher amounts of CNTs was increased just by $17 \%$ and $9 \%$ compared to the strength of specimen CNTs-0. After 28 days of curing the above mentioned difference for the specimens containing smaller amounts of CNTs reached $44.6 \%$, while for specimens containing higher amounts of CNTs the flexural strength was increased just by $18.3 \%$ and $6.6 \%$ compared to the strength of specimen CNTs- 0 . The results obtained in our study indicate that the trends of changes in flexural strength correspond to the changes in compressive strength, but the gain in flexural strength was higher than the gain in compressive strength.

\section{Conclusions}

The effects of multi-walled CNTs, dispersed in carboxyl-methylcellulose using ultrasonic treatment, on the properties of water solutions, fresh cement pastes and hardened specimens were investigated. It can be stated that $0.00005 \%-$ $0.00500 \%$ amounts of CNTs have an insignificant effect on the rheological properties of fresh cement paste - decrease the dynamic viscosity of water solutions approximately $15 \%$, whereas higher amounts of CNTs $(0.05 \%$ and $0.5 \%)$ increase the dynamic viscosity from 1.3 to 4.7 times. It can be stated that $0.00005 \%-0.00500 \%$ amounts of CNTs increase the compressive strength of hardened cement paste by $38.07 \%, 42.2 \%$ and $42.39 \%$ and the flexural strength by $40.1 \%, 41.9 \%$ and $44.6 \%$ respectively after 28 days of curing. The test results proved that $0.05000-0.50000 \%$ of CNTs have a significantly negative effect on rheological and mechanical properties. These amounts of CNTs are marginal for cement paste compositions because higher amounts significantly deteriorate cement paste hydration parameters.

\section{References}

Ajayan, P. M. (1999). Nanotubes from carbon. Chemical Reviews, 99(7), 1787-1799. https://doi.org/10.1021/cr970102g

Bandaru, P. R. (2007). Electrical properties and applications of carbon nanotube structures. Journal of Nanoscience and Nanotechnology, 7(4-5), 1239-1267. https://doi.org/10.1166/jnn.2007.307

Bandow, S., Chen, G., Sumanasekera, G. U., Gupta, R., Yudasaka, M., Iijima, S., \& Eklund, P. C. (2002). Diameter-selective resonant Raman scattering in double-wall carbon nanotubes. Physical Review B, 66(7), 075416. https://doi.org/10.1103/physrevb.66.075416

Campillo, I., Dolado, J. S., \& Porro, A. (2004). High-performance nanostructured materials for construction. In P. J. M. Bartos, J. J. Hughes, P. Trtik, \& W. Zhu (Eds.), Nanotechnology in construction (pp. 215-225). Cambridge, UK: Thomas Graham House. https://doi.org/10.1039/9781847551528-00215

Cwirzen, A., Habermehl-Cwirzen, K., \& Penttala, V. (2008). Surface decoration of carbon nanotubes and mechanical properties of cement/carbon nanotube composites. Advances in Cement Research, 20(2), 65-73. https://doi.org/10.1680/adcr.2008.20.2.65

Cwirzen, A., Habermehl-Cwirzen, K., Nasibulin, A., Kaupinen, E., Mudimela, P., \& Penttala, V. (2009). SEM/AFM studies of cementitious binder modified by MWCNT and nano-sized Fe needles. Materials Characterization, 60(7), 735-740. https://doi.org/10.1016/j.matchar.2008.11.001

Esawi, A. M. K., \& Farag, M. M. (2007). Carbon nanotube reinforced composites: potential and current challenges. Materials and Design, 28(9), 2394-2401. https://doi.org/10.1016/j.matdes.2006.09.022

Harrison, B. S., \& Atala, A. (2007). Carbon nanotube applications for tissue engineering. Biomaterials, 28(2), 344-355. https://doi.org/10.1016/j.biomaterials.2006.07.044

He, X., Kitipomchai, S. C. M. W., \& Leiw, K. M. (2005). Modeling of van der Waals force for infinitesimal deformation of multiwalled carbon nanotubes treated as cylindrical shells. International Journal of Solids and Structures, 42(23), 6032-6047. https://doi.org/10.1016/j.ijsolstr.2005.03.045

Laukaitis, A., Keriene, J., Kligys, M., Mikulskis, D., \& Lekunaite, L. (2012). Influence of mechanically treated carbon fibre additives on structure formation and properties of autoclaved aerated concrete. Construction and Building Materials, 26(1), 362-371. https://doi.org/10.1016/j.conbuildmat.2011.06.035

Lavin, J. G., Subramoney, S., Ruoff, R. S., Berber, S., \& Tománek, D. (2002). Scrolls and nested tubes in multiwall carbon nanotubes. Carbon, 40(7), 1123-1130. https://doi.org/10.1016/s0008-6223(02)00050-7 
Li, G. Y., Wang, P. M., \& Zhao, X. (2005). Mechanical behavior and microstructure of cement composites incorporating surfacetreated multi-walled carbon nanotubes. Carbon, 43(6), 1239-1245. https://doi.org/10.1016/j.carbon.2004.12.017

Li, G. Y., Wang, P. M., \& Zhao, X. (2007). Pressure-sensitive properties and microstructure of carbon nanotube reinforced cement composites. Cement and Concrete Composites, 29(5), 377-382. https://doi.org/10.1016/j.cemconcomp.2006.12.011

Liu, J. Z., Zheng, Q. S., Wang, L. F., \& Jiang, Q. (2005). Mechanical properties of single-walledcarbon nanotube bundles as bulk materials. Journal of the Mechanics and Physics of Solids, 53(1), 123-142. https://doi.org/10.1016/j.jmps.2004.06.008

Makar, J. M., \& Beaudoin, J. J. (2003). Carbon nanotubes and their application in the construction industry. In P. J. M. Bartos, J. J. Hughes, P. Trtik, \& W. Zhu (Eds.), Nanotechnology in Construction (pp. 331-341). https://doi.org/10.1039/9781847551528-00331

Makar, J. M., Margeson, J. C., \& Luh, J. (2005, 22-24 August). Carbon nanotube/cement composites-early results and potential applications. In Proceedings of the $3^{\text {rd }}$ International Conference on Construction Materials: Performance, Innovations and Structural Implications (pp. 1-10). Vancouver, Canada. https://nrc-publications.canada.ca/eng/view/object/?id=8b008ccac122-44e1-a221-b307cb2229cc

Malarkey, E. B., \& Parpura, V. (2007). Application of carbon nanotubes in neurobiology. Neurodegenerative Diseases, 4(4), 292299. https://doi.org/10.1159/000101885

Musso, S., Tulliani, J. M., Ferro, G., \& Tagliaferro, A. (2009). Influence of carbon nanotubes structure on the mechanical behavior of cement composites. Composites Science and Technology, 69(11-12), 1985-1990. https://doi.org/10.1016/j.compscitech.2009.05.002

Peigney, A., Laurent, C., Flahaut, E., Bacsa, R. R., \& Rousset, A. (2001). Specific surface area of carbon nanotubes and bundles of carbon nanotubes. Carbon, 39(4), 507-514. https://doi.org/10.1016/s0008-6223(00)00155-x

Salvetat, J. P., Bonard, J. M., Thomson, N. H., Kulik, A. J., Forro, L., Benoit, W., \& Zuppiroli, L. (1999). Mechanical properties of carbon nanotubes. Applied Physics A: Materials Science and Processing, 69(3), 255-260. https://doi.org/10.1007/s003390050999

Sobolev, K., \& Shah, S. P. (2015). Nanotechnology in Construction. Proceedings of NICOM5. Springer. https://doi.org/10.1007/978-3-319-17088-6

Srivastava, D., Wei, C., \& Cho, K. (2003). Nanomechanics of carbon nanotubes and composites. Applied Mechanics Reviews, 56(2), 215-230. https://doi.org/10.1115/1.1538625

Sumio, I. (1991). Helical microtubes of graphitic carbon. Nature, 354(2), 56-58. https://doi.org/10.1038/354056a0

Xu, S., Liu, J., \& Li, Q. (2015). Mechanical properties and microstructure of multi-walled carbon nanotube-reinforced cement paste. Construction and Building Materials, 76, 16-23. https://doi.org/10.1016/j.conbuildmat.2014.11.049

Yakovlev, G., Keriene, J., Gailius, A., \& Girniene, I. (2006). Cement based foam concrete reinforced by carbon nanotubes. Materials Science-Medziagotyra, 12(2), 147-151. http://dspace.vgtu.lt/handle/1/220 